\title{
Urgences
}

\section{Michel Savard, Cahiers d'anatomie (complicités), Saint-Lambert, Le Noroît, 1985, 157 p.}

\section{Claire Bienvenue}

Numéro 13, mars 1986

\section{Éclats d'atelier}

URI : https://id.erudit.org/iderudit/025249ar

DOI : https://doi.org/10.7202/025249ar

Aller au sommaire du numéro

\section{Éditeur(s)}

Urgences

\section{ISSN}

0226-9554 (imprimé)

1927-3924 (numérique)

Découvrir la revue

Citer ce compte rendu

Bienvenue, C. (1986). Compte rendu de [Michel Savard, Cahiers d'anatomie (complicités), Saint-Lambert, Le Noroît, 1985, 157 p.] Urgences, (13), 115-118. https://doi.org/10.7202/025249ar d'utilisation que vous pouvez consulter en ligne.

https://apropos.erudit.org/fr/usagers/politique-dutilisation/ 
Beaucoup plus qu'une série de fragments biographiques, ce recueil nous livre l'anecdote comme texte, la peau comme tissu, le corps comme prose. Au lecteur de se laisser prendre dans cette trame du grave.

\section{Michel Savard: Cahiers d'anatomie (complicités), Saint-Lambert, Le Noroît, 1985, 157 p. Avec six des- sins de Martin Cormier.}

Nous entrons, sur la pointe des yeux, dans un livre que l'on effleure d'abord. Silences complices,

(..) où tu cherches

à distinguer par la baie zébrée d'eau

quelque lumière dans ton noir (p. 16).

La lumière s'infiltre tout au long du recueil et fait "brasiller l'eau de glace" (p. 12). Elle est lumière de la lune, des étoiles, de laube, du jour, du soleil... de la lampe "araignée lumineuse au bout d'un fil" (p. 53), du lampadaire, des néons, de la chandelle... Elle est reflet, faisceau, éblouissement... Et voilà que l'on découvre, sur la route des phrases, les traces d'une histoire qui, en poèmes d'amours, "soudain s'allúme" (p. 13).

Le poète

ravive l'arôme de la mèche

et celui du souffle qui la souffla (p. 11).

Tel le vieil aquarelliste,

touche par touche

ses doigts réchauffent le petit carré de toile $\{\rho .25\}$.

"Un jour c'était" revient (dix fois dans le livre) comme une formule incantatoire pour retrouver le charme perdu, la douce mélodie de celle déjà loin, étoile nébuleuse en traînées de lumière sur la mémoire, messagère lointaine...

L'imparfait de l'indicatif (...), ce temps cruel qui nous présente la vie comme quelque chose d'éphémère (Proust).

Le lecteur participe à cette grande symphonie inachevée reprise par le poète dans un présent défiant les barrières du temps: 
les ponts-levis du temps

s'abaissent devant celle

qui déverse l'étrange sublime

sur mes mondes lunaires (p. 42).

Du même auteur: Forages, poèmes, également avec dessins de Martin Cormier, au Noroît, 1982. Cette présence de l'os dans les deux recueils nous ramène à l'élément essentiel et relativement permanent du corps. Du périssable reste l'impérissable:

$$
\begin{aligned}
& \text { tu vois } \\
& \text { je ne t'oublie pas } \\
& \text { toi (p. 154). }
\end{aligned}
$$

Cahiers d'anatomie où il dissèque minutieusement ses amours passées, comme dans l'espoir d'une certaine résurrection.

Le livre se divise en douze petits cahiers, au rythme répété des saisons. D'abord, sous l'exergue de l'amour inextinguible, déambulent René Char, Roland Barthes et Henry Miller. Chaque partie se trouve, par la suite, discrètement séparée par une feuille grise, le tout assemblé sous couverture vert tendre:

gris ou vert c'est selon

qu'il s'alarme ou non (p. 12).

Les poèmes sont brefs, imprimés en gros caractères, la présentation très aérée.

"Que dire, que dire" (dix fois dans le livre)...

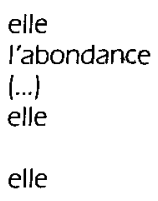

Malgré l'absence, malgré l'absente, les souvenirs foissonnent et s'inscrivent dans le réel:

de l'oeil à la main je transmets

cette fringale que j'ai de toi (p. 129).

Elle: ta beauté, ta tendresse, tes schistes, tes châtoiements, tes désirs... une piété tendre, des gémissements de plaisir, un quotidien de vin, de dentelles... l'omniprésence du corps...

Puis à tout moment

frissonner (p. 38). 
Le geste du plus charnel amour déborde, le mot se fait plus sensuel:

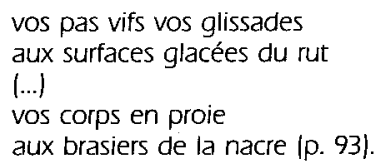

Puis le temps, sur le corps, sur l'amour, comme une pioche, "sape/sourdement les alvéoles des os/et les cloisons des vaisseaux" (p. 87):

(...) vous refaites le compte des muscles des organes rien ne manque un peu du coeur peut-être ( $\rho$. 113).

"Je suis seule". Vertige d'une solitude:

une chaîne un boulet on ne choisit pas

le pied (p. 119).

Aux frissons de volupté, de bonheur, succède le grelottement:

à l'épreuve du feu on se refait une raison pour l'inutile (p. 150).

"L'encre sèche amère" écrit le poète...

je t'écrirais que $(.$.

(...) mais tu n'existes pas

hormis ces souvenirs ces fragments

petites ruptures du réel (p. 156).

Nous retrouvons, sous sa plume, des allusions à la peinture, à la photographie et au cinéma. Chaque poème est un petit objet d'art minutieusement et amoureusement gravé dans et par les mots:

L'art ne fait que des vers, le coeur seul est poète (Chénier).

Plusieurs des textes de ce recueil ont déjà été publiés dans Estuaire (nos 22 et 26) sous les titres "Gloires des nébuleuses" et "Repentir". Repentirs dans "I'étrange navigation/des invisibles" (p. 20):

Toutes les bribes de crayonnage, tous les ratages, tous les repentirs, tous les essuie-pinceaux du peintre (Goncourt).

Le poète reprend "le compte des extases" (p. 109). Les feuilles tombent, tournent et 
tourbillonnent sans fin:

Le poème est l'amour réalisé du désir demeuré désir (Char, ici en exergue).

Nous ne prétendons pas avoir donné un éclairage a giorno de ce magnifique recueil aux reflets irisés. Seulement "quelques chants effleurés", "quelques touches"...

à ce qui consume

à l'inextinguible

à nos passions ces folies

sans lesquelles nos vies (Savard, Estuaire, no 22)

Claire Bienvenue

\section{Michelle Dubois, Le coeur corsaire, Rimouski, Editeq, 1985, $71 \mathrm{p}$.}

Qui a Le coeur corsaire dans les mains, s'arrête un moment au titre, et peut certainement sinon "palper le coeur des choses" (p. 11), du moins, par un détour ludique, glisser du coeur au corps, parenté phonétique, puis, du coeur à l'aire du corps. Cette anagramme partielle, "corsaire" devenant l'aire du corps, pourrait s'avérer purement gratuite si le texte lui-même ne venait confirmer l'intuition et le plaisir qui ont engendré cette lecture. Quatre parties: d'abord "TERRE À TERRE", "LE COEUR CORSAIRE" fait des "ESCALES" et nous annonce le "CORPS DU DÉLIT", surtout avec le poème "CORPS À COEUR". Ce seul "CORPS À COEUR" nous révèle le tissu du texte, articulant un imaginaire où le corps et le coeur ouvrent grand leurs portes pour une quête réciproque, voire une symbiose, qui permettra au sang d'agir comme un courant de réunification entre le coeur symbolique et le corps agi, parlé, écrit, donné. Le coeur, dans un corps serré, fragmenté, se régénère en un coeur à son tour serré, éclaté, vivant, qui parle au corps, le conquiert(?), et se réunifie dans la parole.

Qui a Le coeur corsaire dans les mains, plus que Michelle Dubois? Voyez comment la main, dans cette poésie, n'ignore jamais le coeur, et le suit dans le même vers, ou encore le complète, l'affirme, quelques vers plus loin presque à chaque fois que ce motif réapparaît dans l'oeuvre. Le coeur, lui, à son tour, alimentera l'émouvante gestuelle du corps, l'émouvante geste du parcours des mains dans le texte. "Mon coeur enfin réveillé se jette dans mes mains" (p. 49). Congruence! Mais ce grand voyageur n'aborde pas toujours "en conquérant au domaine du cri" (p. 49). Même "sur l'innommable flotte une rare lumière" (p. 12) et parfois c'est l'essoufflement qui "tient lieu de coeur" (p. 18). Dans la fibre du texte, les routes, les trottoirs, comme les yeux, semblent vouloir glisser dans le chaos. Quelles balises seront alors les nôtres pour suivre "le cercle de la paix/le halo de vie (quil/fait tourner le coeur" (p. 23)? Si la main elle-même est en quête de lieux, de plaine endormie, les coeurs en danger sont "tournés en pics à glace" 